\title{
EFFECTS OF IONTOPHORETICALLY RELEASED PEPTIDES ON PRIMATE SPINOTHALAMIC TRACT CELLS ${ }^{1}$
}

\author{
W. S. WILLCOCKSON, J. M. CHUNG, Y. HORI, K. H. LEE, AND W. D. WILLIS ${ }^{2}$ \\ Marine Biomedical Institute, University of Texas Medical Branch, Galveston, Texas 77550 \\ Received June 10, 1983; Revised September 28, 1983; Accepted September 29, 1983
}

\begin{abstract}
The peptides substance P (SP), methionine-enkephalin (M-ENK), leucine-enkephalin (L-ENK), and cholecystokinin (CCK) were released iontophoretically near spinothalamic tract (STT) cells in anesthetized monkeys and STT-like cells in decorticate, spinalized monkeys. Peptide effects were observed on background discharges, firing induced by release of glutamate, and activity evoked by pinching the skin.

SP could have any of several actions on STT cells, including excitation, inhibition, or biphasic effects. Multiple effects often resulted while recording from an individual cell when the dose or the electrode position was changed. M-ENK and L-ENK generally inhibited STT cells, and in some cases it was possible to demonstrate a reversal of the inhibition by naloxone. CCK also caused an inhibition that was additive with that produced by L-ENK.

The multiple actions of SP on STT cells suggests the possibility that there may be more than one type of SP receptor on STT cells, although alternative explanations should be considered. Inhibition of STT cells by M- and L-ENK is consistent with the known analgesic action of opiates through spinal cord mechanisms. CCK has an action on STT cells similar to that of the enkephalins.
\end{abstract}

A number of peptides are concentrated in neural elements of the dorsal horn of the mammalian spinal cord and are putative neurotransmitters (Emson, 1979; Nicoll et al., 1980). These include substance P (SP), somatostatin, cholecystokinin (CCK), enkephalin, neurotensin, thyrotropin-releasing hormone, avian pancreatic polypeptide, vasoactive intestinal polypeptide, and others (Hökfelt et al., 1975a, b, 1978, 1979; Takahashi and Otsuka, 1975; Kardon et al., 1977; Pickel et al., 1977; Hunt et al., 1980, 1981; Aronin et al., 1981; Gibson et al., 1981; Glazer and Basbaum, 1981; DiFiglia et al., 1982; Yaksh et al., 1982).

SP and somatostatin have been demonstrated in dorsal roots and dorsal root ganglion cells, and their concentration in the dorsal horn decreases following dorsal rhizotomy (Hökfelt et al., 1975b, 1976; Takahashi and Otsuka, 1975; Chan-Palay and Palay, 1977). Thus, these peptides are candidate neurotransmitters of primary afferent fi-

\footnotetext{
${ }^{1}$ This work was supported by Grants NS 09743 , NS 11255 , and NS 18830 from the National Institutes of Health and by a grant from the Moody Foundation. We wish to thank Helen Willcockson for her expert technical assistance in the surgical preparation of the animals and in the art work. We thank also G. Gonzales for her help with the histology and Phyllis Waldrop for typing the manuscript.

${ }^{2}$ To whom correspondence should be addressed, at Marine Biomedical Institute, 200 University Boulevard, Galveston, TX 77550.
}

bers. SP and somatostatin are also contained in interneuronal cell bodies in the dorsal horn and in axons descending from the brainstem (Chan-Palay, 1979; Bowker et al., 1981; Hunt et al., 1981; Johansson et al., 1981; Gilbert et al., 1982).

CCK may also be a primary afferent transmitter in some species, including the cat (Maderdrut et al., 1982). Other peptides, including enkephalin, neurotensin, and thyrotropin-releasing hormone, have not been demonstrated in primary afferent fibers but are constituents of neurons of the dorsal horn and/or of descending tracts (Hökfelt et al., 1975a, 1979; Aronin et al., 1981; Bowker et al., 1981; Hunt et al., 1981; Johansson et al., 1981; Gilbert et al., 1982).

It is known that several peptides can excite or inhibit the activity of dorsal horn interneurons when ejected from micropipettes introduced into the dorsal horn. For example, SP has been shown to produce a delayed but long-lasting excitation of dorsal horn interneurons (Henry et al., 1975; Henry, 1976; Randić and Miletić, 1977; Sastry, 1979b; Zieglgänsberger and Tulloch, 1979a). CCK has also been reported to excite dorsal horn neurons (Jeftinija et al., 1981), as has neurotensin (Miletic and Randić, 1979). Leucine- and methionine-enkephalin (LENK and M-ENK) and somatostatin, on the other hand, cause a depression of the discharges of many dorsal horn interneurons (Duggan et al., 1977b; Randić and Miletić, 
1978; Satoh et al., 1979; Zieglgänsberger and Tulloch, 1979b).

The present work is an investigation of the actions of the peptides substance $P$, leucine- and methionine-enkephalin, and cholecystokinin on primate spinothalamic tract (STT) cells. These substances were released by iontophoresis near STT cells, and their effects on the discharges evoked by glutamate pulses or by noxious stimulation of the skin were assessed. A preliminary report of some of the results has been made in abstract form (Willcockson et al., 1983). The companion paper (Willcockson et al., 1984) describes the responses of STT cells to iontophoretic application of amino acids and amines.

\section{Materials and Methods}

Experiments were performed on 16 anesthetized monkeys (Macaca fascicularis) weighing 2.0 to $3.2 \mathrm{~kg}$. The experimental procedure for these studies was identical to that described in the preceding paper (Willcockson et al., 1984). Decorticate, spinalized animals were used in three of the experiments. STT and STT-like cells of the dorsal horn were identified by antidromic activation from the contralateral thalamus (Trevino et al., 1973) or from the lateral funiculus of the contralateral upper cervical cord (Willcockson et al., 1984).

Drug concentrations and $\mathrm{pH}$ were as follows: $\mathrm{L}$-monosodium glutamate (Sigma), $0.2 \mathrm{M}, \mathrm{pH} 8.5$; M-ENK (Sigma), $10 \mathrm{mM}$, pI I 5.0; L-ENK (Sigma, Beckman-two experiments, $10 \mathrm{mM}, \mathrm{pH}$ 5.0); SP-triacetate salt (Sigma); SP (Beckman - three experiments, $5 \mathrm{mM}$, pH 5.0); CCK (Sigma), 250 units $/ \mathrm{ml}$, pH 5.0; and naloxone hydrochloride, $0.1 \mathrm{M}, \mathrm{pH}$ 4.5. All compounds were made up in sterile, deionized $\mathrm{H}_{2} \mathrm{O}$ immediately before filling the electrodes. All drugs, except glutamate (Glu), were applied with cationic current. Retaining currents were always $\leq 7$ $\mathrm{nA}$; current neutralization was employed during all drug applications.

The drugs were tested against background, Glu-induced, or mechanically evoked activity, as described previously (Willcockson et al., 1984). Data compilation and analysis of peptide effects were accomplished as for experiments using the amines. Marks were made by passing current through the carbon-fiber microelectrodes to show recording sites.

\section{Results}

Peptide effects were examined on a total of 52 cells in 16 experiments. In most cases, the effects of amino acids and amines were also tested on the same cells (see Willcockson et al., 1984). STT cells and STT-like cells examined in spinalized animals were found at depths of 600 to $2070 \mu \mathrm{m}$ from the dorsal surface of the spinal cord, and most marks were located in the upper five laminae of the dorsal horn. The locations of sites at which recordings were made from STT cells are summarized in Figure 1 of the preceding paper (Willcockson et al., 1984). Antidromic latencies in the animals with an intact neuraxis ranged from 2.6 to $13 \mathrm{msec}$ and in spinalized animals ranged from 2.8 to $7.8 \mathrm{msec}$. These latencies correspond to conduction velocities appropriate for myelinated axons (12 to $60 \mathrm{~m} / \mathrm{sec}$ ). Thresholds for antidromic activation ranged from 20 to $750 \mu \mathrm{A}$ for STT cells and $200 \mu \mathrm{A}$ to $1 \mathrm{~mA}$ for cells antidromically activated in spinalized animals. Responses of STT cells to innocuous and noxious stimuli allowed the following classification (Chung et al., 1979): wide dynamic range (WDR) STT cells, 31; high threshold (HT), 6; low threshold (LT), 1; deep (D) cells, 1 . One cell could not be classified. Of cells recorded in spinalized animals, 9 were WDR, 1 was HT, and 2 were LT.

There was no apparent correlation between differences in drug effects and cell location within the dorsal horn, conduction velocity, or classification (WDR, HT, LT). No difference was observed in the responses to peptides or naloxone in anesthetized or in spinalized preparations.

$\mathrm{SP}$ is often regarded as a neurotransmitter that has an excitatory action on nociceptive neurons of the dorsal horn. Although we confirm previous observations, we were impressed by the observation that SP often produced complex effects on STT cells (Table I). In addition to purely excitatory, purely inhibitory, or no effects, we often observed biphasic effects (excitation followed by inhibition or the reverse) or different types of actions, depending upon the position of the microelectrode array or on iontophoretic current strength (11 of 27 STT cells). For example, in one cell, excitation, inhibition followed by excitation, excitation followed by inhibition, and no effect were all noted. In another two cells either excitation or inhibition followed by excitation was caused by $\mathrm{SP}$ release. The remainder of the cells exhibiting multiple actions of SP had other combinations of effects. In nine cells, the multiple effects were apparently due to changes in the iontophoretic current used to apply SP. Multiple responses to SP were otherwise due to changes of position of the electrode relative to the cell under investiga-

TABLE I

Peptide effects on STT cells ${ }^{a}$

\begin{tabular}{|c|c|c|c|c|c|c|c|}
\hline Drug $^{b}$ & $\begin{array}{l}\text { Excita- } \\
\text { tion }^{c}\end{array}$ & $\begin{array}{c}\text { Inhibi- } \\
\text { tion }^{c}\end{array}$ & $\begin{array}{c}\text { No } \\
\text { Effect }\end{array}$ & $\begin{array}{l}\text { Biphasic } \\
\text { Effect }^{d}\end{array}$ & $\begin{array}{l}\text { Multiple } \\
\text { Effects }^{\text {e }}\end{array}$ & Total & $\begin{array}{l}\text { Threshold } \\
\text { (nA) }\end{array}$ \\
\hline \multicolumn{8}{|c|}{ A. vs. Glu Activity } \\
\hline M-ENK & $1(56 \%)^{c}$ & $22(99 \%)$ & 4 & 0 & 1 & 28 & $25-150$ \\
\hline L-ENK & 0 & $29(100 \%)$ & 2 & 0 & 0 & 31 & $50-150$ \\
\hline SP & $3(59 \%)$ & $2(81 \%)$ & 3 & 8 & 11 & 27 & $25-100$ \\
\hline CCK & 0 & $6(89 \%)$ & 0 & 0 & 0 & 6 & $25-50$ \\
\hline \multicolumn{8}{|c|}{ B. vs. Background Activity } \\
\hline M-ENK & 0 & $4(69 \%)$ & 0 & 0 & 0 & 4 & $50-150$ \\
\hline L-ENK & 0 & $5(77 \%)$ & 0 & 0 & 0 & 5 & $50-150$ \\
\hline SP & 0 & $1(40 \%)$ & 2 & 1 & 3 & 6 & $25-150$ \\
\hline CCK & 0 & $2(60 \%)$ & 0 & 0 & 0 & 2 & $25-50$ \\
\hline \multicolumn{8}{|c|}{ C. vs. Pinch Activity } \\
\hline M-ENK & 0 & $9(100 \%)$ & 4 & 0 & 0 & 13 & $50-150$ \\
\hline L-ENK & 0 & $4(89 \%)$ & 0 & 0 & 0 & 4 & $50-200$ \\
\hline SP & 0 & 0 & 2 & 1 & 0 & 3 & 50 \\
\hline
\end{tabular}

"This table also includes data from STT-like dorsal horn cells in spinal animals. See the text for further details.

${ }^{b}$ Barrel concentrations for M-ENK and L-ENK $=10 \mathrm{mM}$, for SP = $5 \mathrm{mM}$, and for $\mathrm{CCK}=250$ units $/ \mathrm{ml}$.

c The number of cells responding as indicated by heading. In parentheses, the maximum percentage of excitation (column 2) or inhibition (column 3) seen with currents $\leq 150 \mathrm{nA}$.

${ }^{d}$ Biphasic effects include such actions as inhibition followed by excitation or excitation followed by inhibition.

${ }^{e}$ Any combination of single or biphasic effects seen with changes in dose or electrode position relative to the cell. 
tion. This was seen in 7 of the 11 cells exhibiting multiple reactions to SP. There was no apparent correlation between SP effects and the locations of cells in different laminae of the dorsal horn.

In Figures 1 and 2, some of the various effects of SP on STT cells are illustrated. Figure $1 A$ shows the location and receptive field (insets) of an STT cell and a singlepass peristimulus time histogram of the responses of this cell to graded mechanical stimuli. This STT cell was classified as a WDR cell. In Figure 1, $C$ and $D$, a currentrelated excitation of this cell followed iontophoretic application of SP at one position of the multi-barrel microelectrode. The excitation was manifested both as an increase in the responses to Glu pulses (Glu applied for 5 sec every $10 \mathrm{sec}$ ) and as an increase in background activity (seen between the Glu responses). The largest excitation occurred after the iontophoretic current was stopped in Figure 1D. The excitation then persisted for the remainder of the time shown in the histogram. Following these recordings, the microelectrode array was moved to another nearby track. The same STT cell was then found, as shown by its depth, the latency of the antidromic action potential, and the receptive field. In this microelectrode position, SP at $50 \mathrm{nA}$ produced a strong inhibition followed by an increase in activity after the current ceased. A similar effect was observed on both Glu responses (Fig. $1 E$ ) and pinch-evoked firing (Fig. $1 B)$.

In Figure 2 another WDR STT cell was tested with SP. From one microelectrode position, SP appeared only to excite the cell in a current-related fashion (Fig. $2 C$ ). From another microelectrode position (Fig. 2D), SP caused a delayed inhibition. Figure $2 E$ illustrates still another effect of SP after the electrode was moved to a different point. Here $50 \mathrm{nA}$ of SP produced excitation and then inhibition. This response was reproduced by Glu at this same microelectrode position, as seen in Figure $2 B$.

Iontophoretic application of M-ENK had predominantly inhibitory effects on STT cells and STT-like cells in spinalized animals. When tested against the responses to Glu, M-ENK depressed 22 of 28 cells (79\%). Inhibitory responses were often slow in onset and of long duration, although this was not always so. In four cells (one in a
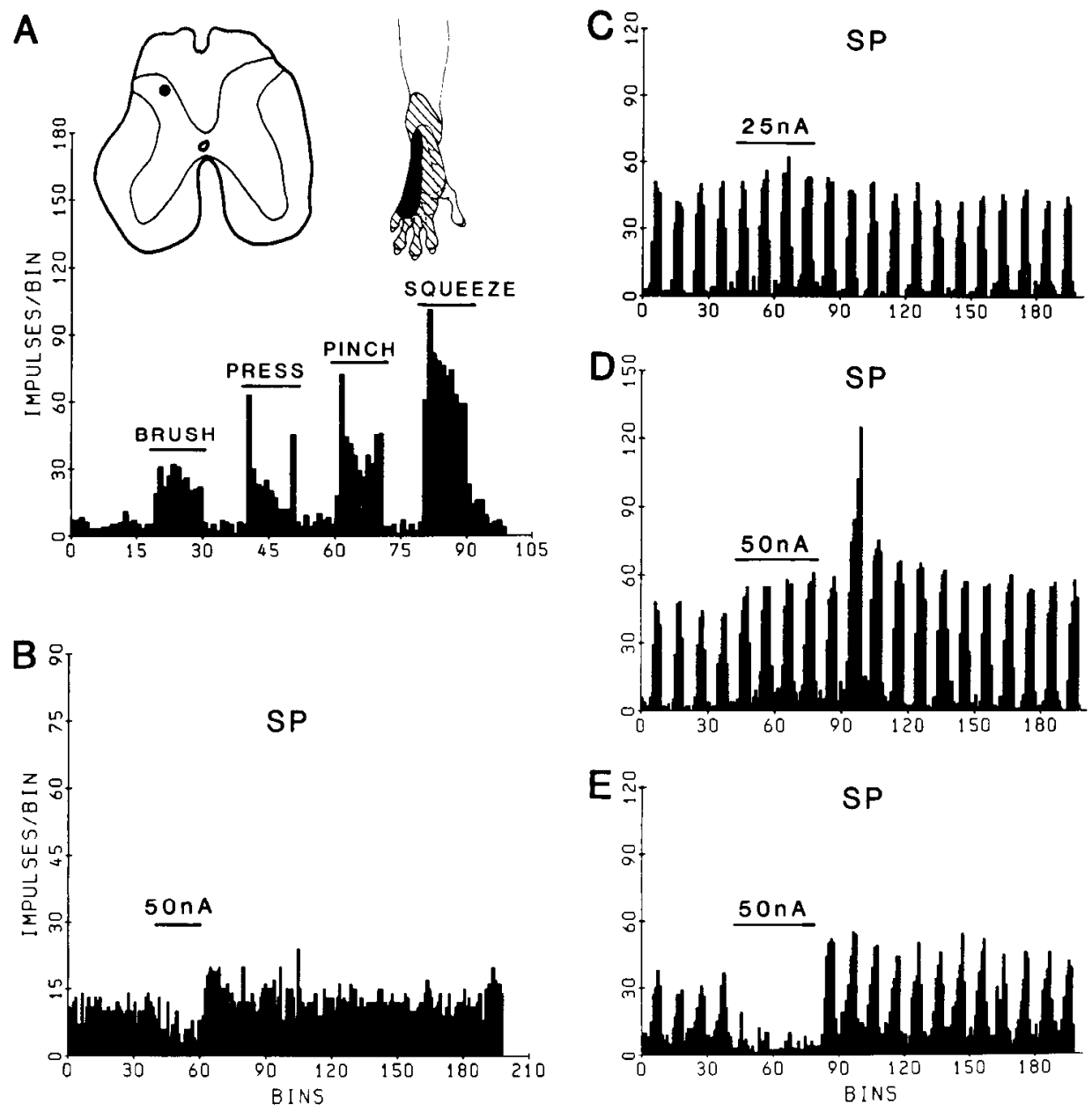

Figure 1. Multiple effects of SP on an STT neuron. A, Insets show cell location and receptive field. The single-pass peristimulus time histogram shows responses to graded intensities of mechanical stimuli. $B$, Effect of SP on pinch-evoked firing of the cell. Note the inhibition during application followed by an increase in overall activity after the termination of current. $C$ and $D$, SPinduced enhancement of the responses to pulsed release of Glu at two different currents. The electrode was in different positions relative to the cell for recordings seen in $B$ and $C$. $E$, Inhibition, then enhancement of Glu responses after application of SP. This recording was made at the same location as that in $B$. Bin width $=1$ sec for histograms in this and later figures, unless otherwise stated. 

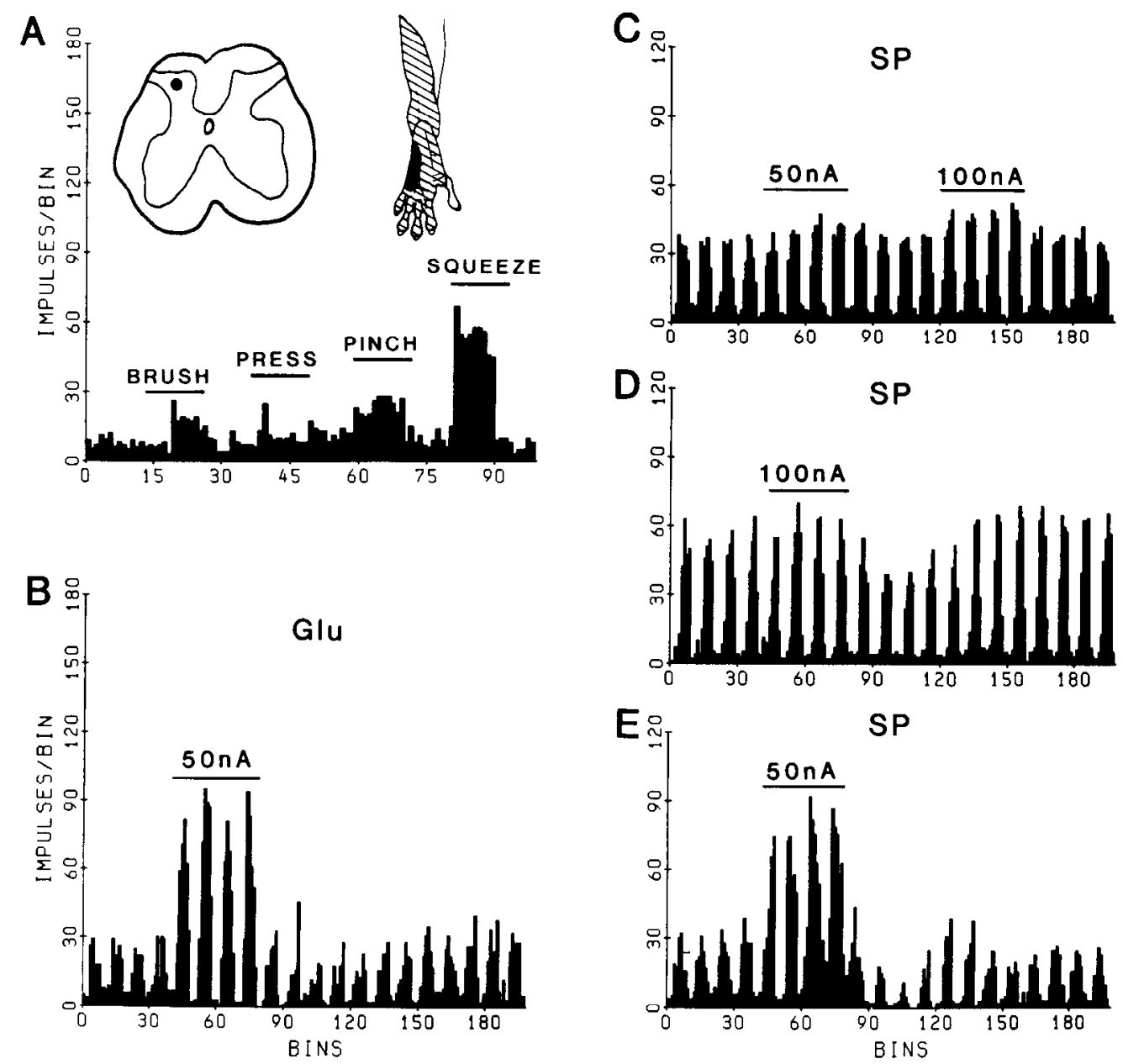

Figure 2. Multiple effects of SP on an STT cell and comparison to action of Glu. A, Insets show STT cell location and receptive field. The single-pass peristimulus time histogram shows activity induced by innocuous and noxious mechanical stimuli. $B$, Effect of Glu applied from one barrel on responses to pulsed Glu release from a separate barrel of the multi-barreled array. $C$, Enhancement of Glu-induced activity by SP. $D$, Effect of $\mathrm{Sp}$ on Glu responses at a different position from the recording site than that for $C$. $E$, Effect of SP on Glu responses at still another electrode position. This recording site was the same spot as that where the histogram in $B$ was recorded. Note the similarity of effects of Glu and SP in $B$ and $E$.

spinalized animal), no effect was seen. One cell in a spinalized animal was apparently excited by M-ENK, and one STT cell showed an inhibition followed by excitation or only inhibition, depending upon the position of the electrode. M-ENK was tested against background activity in four cells (two in spinalized animals); all four were inhibited. M-ENK also reduced activation by pinching in 9 of 13 cells ( 1 in a spinalized animal); in 4 cells ( 1 in a spinalized animal), no effect was seen. In three STT cells, M-ENK was tested on activity evoked by ipsilateral sural nerve stimulation. Nonspecific inhibition was observed in all three cells; that is, there was a similar reduction in background activity and in responses to volleys in A fibers and $C$ fibers.

Naloxone $(0.05 \mathrm{mg} / \mathrm{kg}$, i.v. $)$ was administered following control observations of the inhibitory effects of iontophoresed M-ENK on excitation by pulsed application of Glu. Systemic naloxone by itself did not have a significant effect on background or Glu-induced activity. Following naloxone the M-ENK inhibition was reduced in two of five cells tested (one in a spinalized animal). Maximal reduction of the control M-ENK inhibition of
$37 \%$ and $81 \%$ occurred in 15 and $35 \mathrm{~min}$ in these two cells. Recovery was seen in approximately $1 \mathrm{hr}$. In one cell the M-ENK inhibition was enhanced following naloxone. Recovery in this case occurred within $10 \mathrm{~min}$. In two other cells, naloxone had no apparent effect on the M-ENK response (one cell exhibiting no antagonism by naloxone of M-FNK inhibition was in a spinalized animal).

M-ENK inhibition of STT cells is illustrated in Figures 3 to 5 . Figure 3 shows M-ENK and naloxone effects on an STT cell. In Figure $3 A$, M-ENK reduced the responses of the cell to pulsed release of Glu. In Figure $3 B$, the M-ENK effect was shown to be antagonized 35 min after systemic administration of naloxone. After 90 min (Fig. $3 C$ ), the M-ENK effect was again strong.

Figure 4 shows the inhibitory effect of M-ENK on STT cell activity induced by pinching the receptive field. In Figure $4 D$, the M-ENK effect has been attenuated 10 min after systemic naloxone.

L-ENK also inhibited STT cells. The Glu responses of 29 of 31 cells (93\%) were inhibited by iontophoretic application of L-ENK; no cases of excitation were seen. 

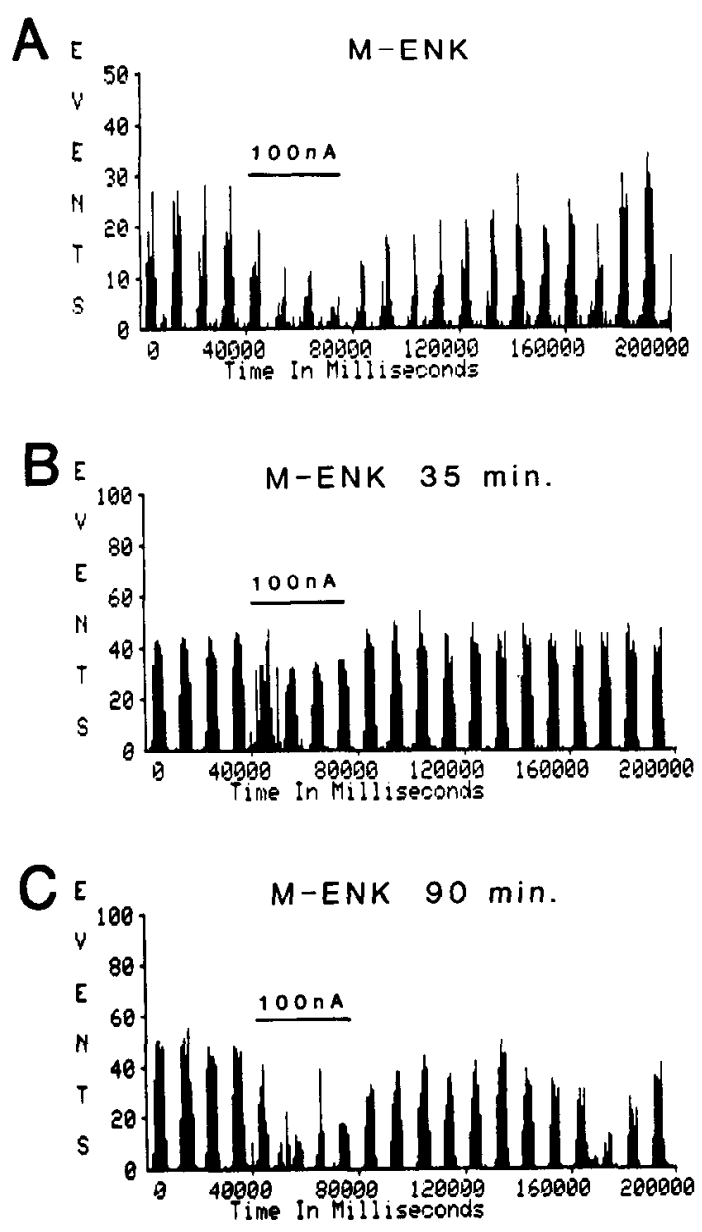

Figure 3. Effects of M-ENK and naloxone on the responses of an STT cell to pulsed release of Glu. The cell's location and receptive field characteristics have been shown in Figure $4 A$ in the preceding paper (Willcockson et al., 1984). A, Inhibition of pulsed Glu responses by M-ENK. The single-pass peristimulus time histogram shows bursts of activity produced by Glu applied for $5 \mathrm{sec}$ at 10 -sec intervals. During the period indicated by the bar, $100 \mathrm{nA}$ of M-ENK were applied. $B$, Thirty-five minutes after naloxone $(0.05 \mathrm{mg} / \mathrm{kg})$ was administered intravenously the response to M-ENK was maximally reduced. $C$, Ninety minutes after naloxone administration the effect of M-ENK had recovered. Bin width $=800$ msec.

L-ENK inhibited the high background activity of all six cells tested and reduced pinch-induced activity in all four cells tested. Of cells in spinal animals contributing to these totals, eight showed inhibition of Glu-induced responses, two showed inhibition of background activity, and one showed inhibition of pinch-induced activity. In Figure 5, M-ENK inhibition is compared to L-ENK inhibition on an STT-like WDR cell in a spinalized animal.

L-ENK's effect was usually of short onset and stopped soon after current termination. This type of effect is illustrated in Figure 5C. However, in some cases the effect of L-ENK was of longer duration. This is seen in Figure 6, where the inhibition produced by L-ENK is compared to that by 5-hydroxytryptamine on responses to pulses of Glu (Fig. 6, $A$ and $B$ ) and pinch-evoked activity (Fig. 6C). The location and receptive field char- acteristics of the STT cell described in Figure 6 were shown in Figure $1 A$.

Naloxone's effect on L-ENK inhibition of Glu-induced responses was tested by both intravenous $(0.05 \mathrm{mg} / \mathrm{kg})$ and iontophoretic administration of naloxone. Systemic naloxone antagonized L-ENK's effect on three dorsal horn WDR STT-like cells in spinalized animals. Maximal reductions of $44 \%, 100 \%$ and $65 \%$ were seen in 10 , 12 , and $2 \mathrm{~min}$. Partial recovery was noted within 20 to $30 \mathrm{~min}$. L-ENK's effect was also examined on one identified STT cell following systemic naloxone administration. Naloxone reduced L-ENK inhibition by $45 \%$ in 13 min, with partial recovery seen in $30 \mathrm{~min}$. Thus, naloxone antagonized the action of L-ENK in all four cases tested. Naloxone inhibited STT cells when applied alone by iontophoresis of $50 \mathrm{nA}$. At $25 \mathrm{nA}$, no significant direct effect of naloxone was observed; hence, this dose was used against the inhibition of Glu responses produced by L-ENK. Three STT cells were tested, but $25 \mathrm{nA}$ of naloxone reduced the L-ENK effect in only one cell; no effect was noted in the other cells.

CCK was applied iontophoretically onto six STT cells. Five of these were classified as WDR cells and one as an LT cell. The Glu-induced responses of all of these cells were strongly inhibited. Tested on background activity, CCK inhibited two of two cells. Thresholds of 25 to 50 nA were required to produce up to $89 \%$ inhibition.

Both CCK and L-ENK were simultaneously applied iontophoretically after control responses to either of these agents alone on Glu-induced activity were obtained. The inhibitory effects of CCK and L-ENK were additive when both compounds were applied together. This observation was made in three of three STT cells.

The additive inhibition of CCK and L-ENK is shown in Figure 7. In Figure 7A, L-ENK produced inhibition of pulsed Glu activity. In Figure $7 B$, CCK produced inhibition at $100 \mathrm{nA}$. When CCK and L-ENK were applied together, each at $100 \mathrm{nA}$, an even greater inhibition was observed.

The effects of the peptides on Glu-induced, background, and pinch-induced firing of the cells are summarized in Table I.

\section{Discussion}

Our finding that SP has a variety of actions on STT cells, depending upon dose or position of the iontophoretic electrode, is intriguing. Previous studies of the action of iontophoretically applied SP have emphasized a delayed excitatory action on nociceptive neurons (Henry et al., 1975; Henry, 1976; Randić and Miletić, 1977; Zieglgänsberger and Tulloch, 1979a; Piercey et al., 1980), although mixed excitatory and depressant actions have been described in both the spinal cord and the cuneate nucleus (Krnjević and Morris, 1974; Henry et al., 1975; Davies and Dray, 1980). Recently, in an in vitro spinal cord preparation, bath application of SP has been found to produce a biphasic hyperpolarization and depolarization of dorsal horn neurons (Murase et al., 1983).

The delayed excitatory action of SP has been explained in a variety of ways, including slow diffusion of the peptide molecule through the extracellular space, an action on the metabolism of the postsynaptic neuron, or 

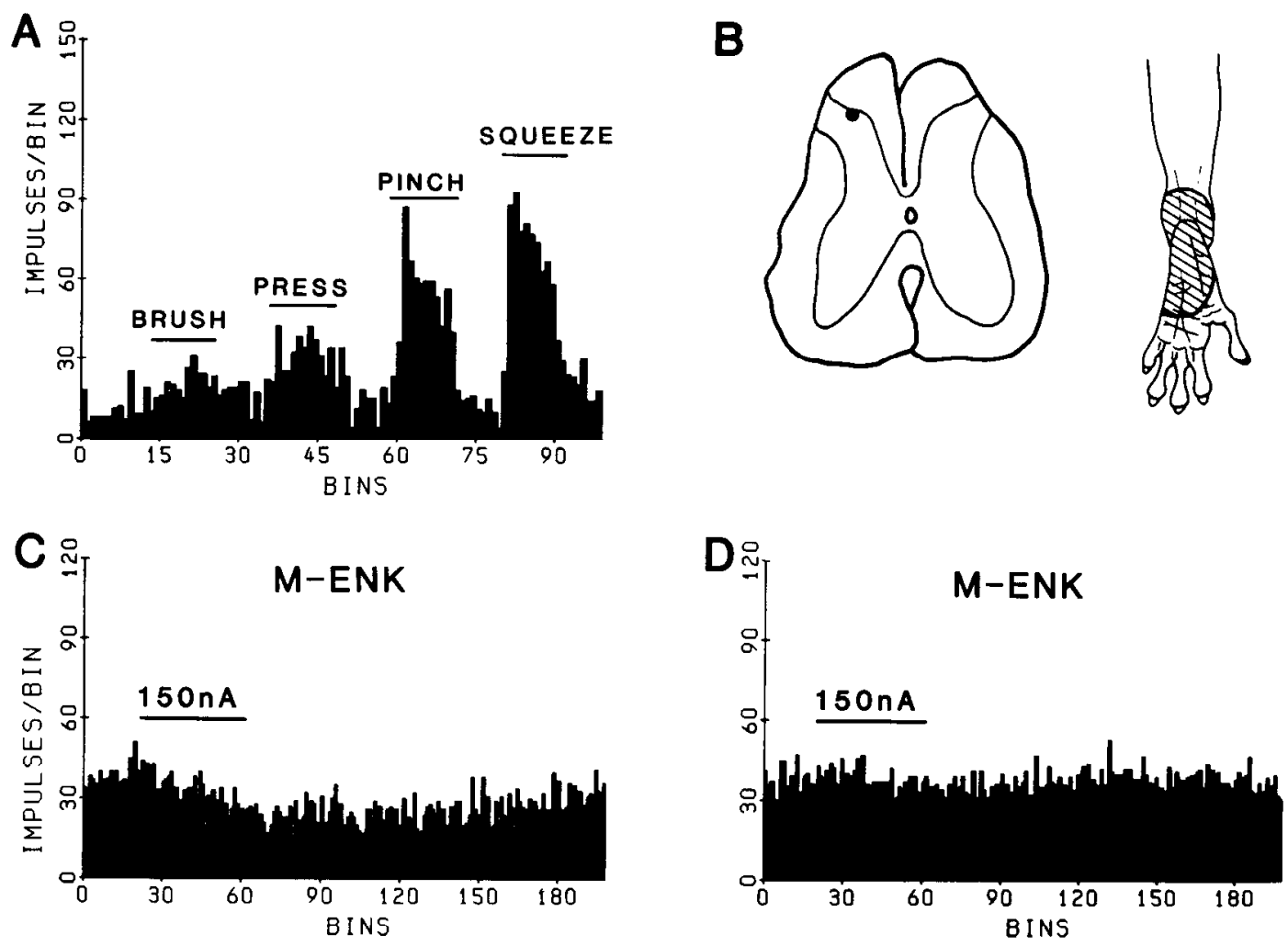

Figure 4. M-ENK reduction of pinch-induced activity of an STT cell and reversal by naloxone. $A$, Responses of the cell to four gradations of mechanical stimuli applied to the cell's receptive field. $B$, Location of cell and receptive field on ipsilateral foot. $C$, M-ENK applied during the period indicated slows the activity of this cell during pinching with a small clip. $D$, Lack of effect of M-ENK on pinch-evoked activity $10 \mathrm{~min}$ after systemic administration of naloxone $(0.05 \mathrm{mg} / \mathrm{kg})$.

an indirect action through release of transmitter or potassium ions from presynaptic elements (Henry et al., 1975; . Henry, 1976). Guyenet et al. (1979) have shown that the ejection of SP from micropipettes is delayed by the retaining current. The depressant action of SP on some interneurons has been ascribed to a current effect (Henry et al., 1975; Henry, 1976) or to a slowly developing depolarization (Krnjević and Morris, 1974). It seems more plausible to us that the depression is due to an inhibitory action of SP, in addition to its excitatory action.

The two opposing actions of SP, excitation and inhibition, could be explained by two different SP receptors. Henry et al. (1975) mentioned the possibility that SP might have different sites of action, and there has been a report favoring the idea of multiple SP receptors (Frederickson et al., 1978). The possibility that SP was fragmenting into different active components in our electrodes has to be considered (cf. Gozlan et al., 1977), but we think that this is unlikely since the peptide was made up immediately before use. Another possibility is that SP acted in part directly on STT cells and in part indirectly through an action on adjacent interneurons or on axon terminals (cf. Puil, 1981). Supporting this idea is the observation of Murase et al. (1983) that the initial hyperpolarization of dorsal horn interneurons by bathapplied SP in a spinal cord slice preparation is blocked by agents that prevent synaptic transmission. However, the possibility of multiple SP receptors should be taken seriously in view of the increasing evidence for multiple receptors in the spinal cord for other peptides, such as the opioid peptides (Fields et al., 1980; Duggan et al., 1981 ), as well as multiple classes of postsynaptic action (Barker et al., 1978).

If there were multiple SP receptors, these might be associated with SP synapses from different sources onto dorsal horn interneurons. For example, SP is contained in synapses of primary afferent fibers, interneurons, and also axons of descending tracts on neurons in the dorsal horn (Hökfelt et al., 1975b, 1976; Chan-Palay and Palay, 1977; Bowker et al., 1981; Hunt et al., 1981; Johansson et al., 1981; Gilbert et al., 1982). An attractive hypothesis would be that SP released from primary afferent fibers might excite STT cells, whereas SP released from interneurons and/or descending axonal projections might inhibit STT cells.

In addition to a postsynaptic action, SP may also have presynaptic effects (Randic et al., 1982).

However, not all of the complex actions of SP need to be explained on the basis of different sites of action of SP. The depression produced by SP following an initial excitation in Figure $2 E$ could be mimicked by a large application of Glu, as shown in Figure $2 B$. A similar postexcitatory depression following Glu application onto dorsal horn interneurons has been attributed by Peet et al. (1983) to refractoriness due to prolonged firing of the cell.

The inhibitory action of the enkephalins was not unexpected. Previous studies have shown that both M-ENK and L-ENK have a predominantly inhibitory action 


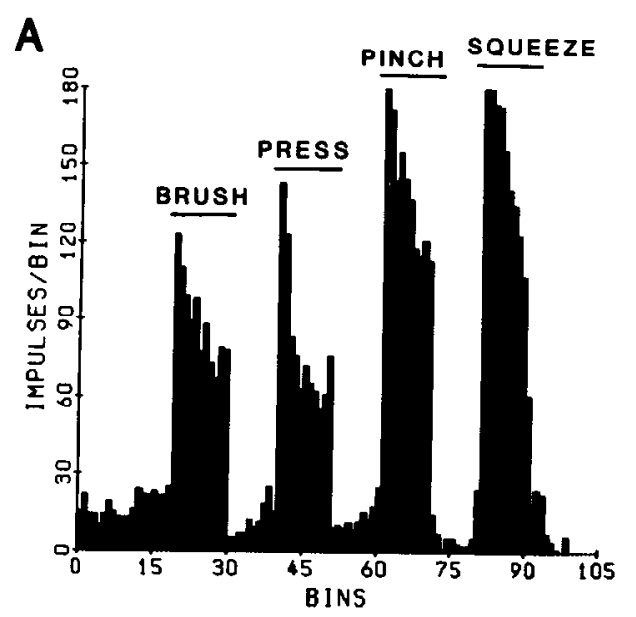

B
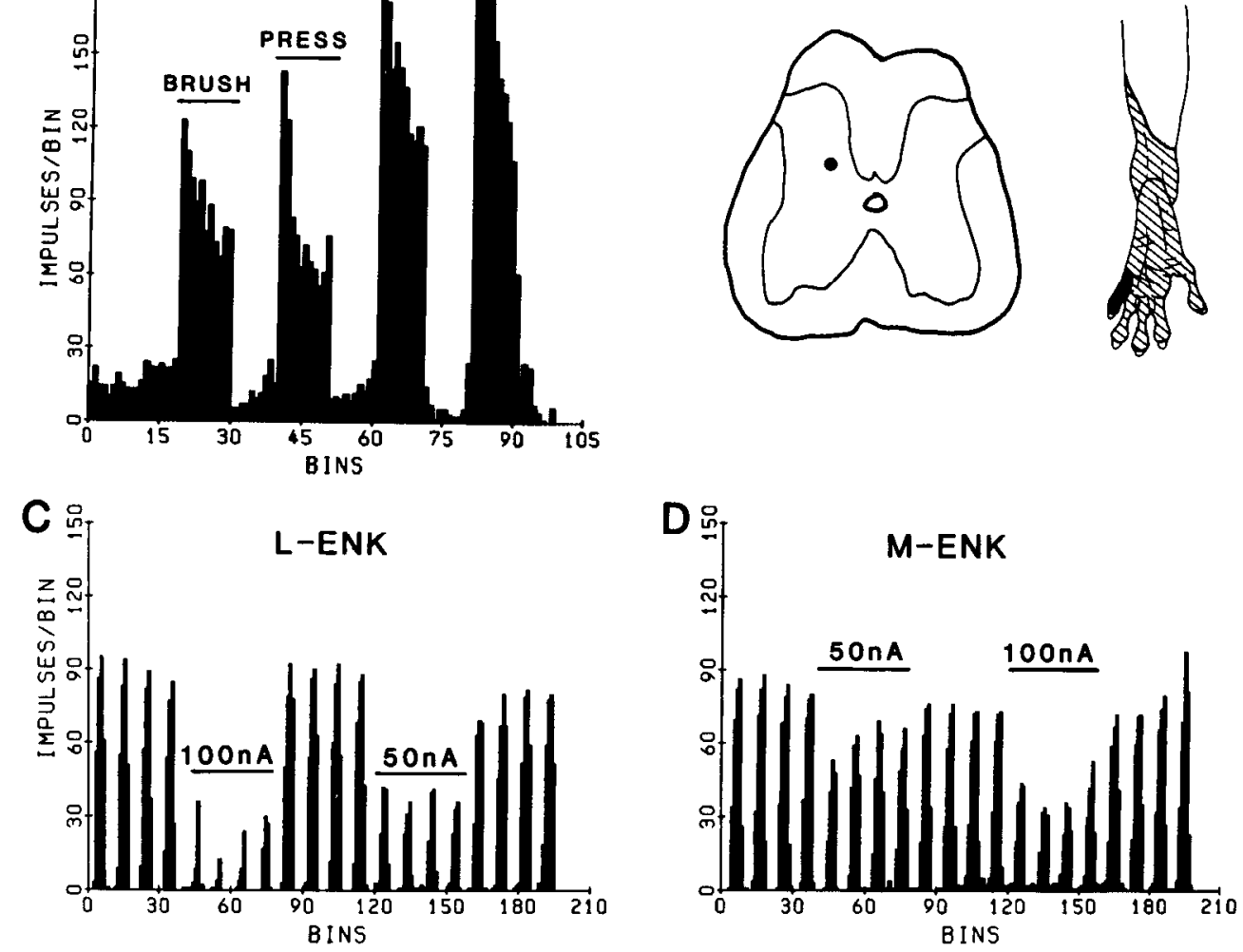

Figure 5. Comparison of L-ENK and M-ENK effects on Glu-induced activity of a nociceptive dorsal horn neuron that projected to the contralateral upper cervical cord. $A$, Single-pass peristimulus time histogram demonstrating the responses of the cell to innocuous and noxious mechanical stimuli. $B$, Cell location and receptive field. This cell was recorded in a spinalized animal and, therefore, may not be an STT cell. $C$ and $D$, L-ENK and M-ENK inhibition of pulsed Glu firing of the cell.

when released iontophoretically near nociceptive dorsal horn interneurons (Duggan et al., 1977b, 1979; Randić and Miletić, 1978; Satoh et al., 1979; Zieglgänsberger and Tulloch, 1979b). In our experiments, as in many previous studies, the inhibitory action of the enkephalins often had a slow onset and long duration. We found that systemically administered naloxone and iontophoretically applied naloxone could often prevent the inhibitory action of the enkephalins. Thus, the inhibition was likely to have been mediated through an action on opiate receptors. The enkephalin effects were tested against responses to Glu pulses in most cases, and thus were presumably due to a postsynaptic action (Zieglgänsberger and Tulloch, 1979b). Although emphasis has been placed in many studies on a presynaptic action of opiates on opiate receptors located on primary afferent terminals (LaMotte et al., 1976; Jessell and Iversen, 1977; MacDonald and Nelson, 1978; Mudge et al., 1979; Sastry, 1979a; however, cf. Duggan et al., 1979), there is also ample evidence for a postsynaptic site of opiate action (Dostrovsky and Pomeranz, 1973; Zieglgänsberger and Bayerl, 1976; Barker et al., 1978; Zieglgänsberger and 'Iulloch, 1979b; Hunt et al., 1980; Aronin et al., 1981; Ruda, 1982).

The fact that there is an opiate-mediated synaptic mechanism in the spinal cord with an action on nociceptive dorsal horn neurons is of importance in the context of pain mechanisms. For example, it is known that analgesia can be produced by an action of opiates at the spinal cord level (reviewed by Yaksh, 1981) and that morphine and other opiates generally have inhibitory actions on nociceptive spinal cord interneurons (Dostrovsky and Pomeranz, 1973, 1976; Belcher and Ryall, 1978; Duggan et al., 1977a, 1981).

It should be noted that, although iontophoretically applied morphine can excite some dorsal horn interneurons, this may in some cases be due to a toxic action of high concentrations of the drug (Duggan et al., 1977a; Belcher and Ryall, 1978; Piercey et al., 1980). Alternatively, excitation by morphine may be related to neuronal response properties, since it is most commonly observed when recordings are made from non-nociceptive cells (Belcher and Ryall, 1978). Systemically administered morphine results in excitation of some neurons in the substantia gelatinosa while inhibiting nociceptive neurons in deeper laminae (Woolf and Fitzgerald, 1981). Thus, analgesia could be due either to a depressant action of opiates on nociceptive neurons or to an excitatory action on inhibitory interneurons or both. There are a variety of opiate receptors, some of which are more sensitive to morphine and others to the enkephalins and other opioid substances; thus morphine may not always have the same action as other opiate substances acting at a spinal cord level. Peripheral nerve stimulation can cause the release of M-FNK-like immunoreactivity from the spinal cord (Yaksh and Elde, 1981), and it is likely 
that opiate release is involved in the mechanism of several procedures involving peripheral nerve stimulation that cause analgesia, such as some forms of transcutaneous nerve stimulation and acupuncture (Sjölund and Eriksson, 1979; cf. Chung et al., 1983; Woolf et al., 1980).

We were surprised to find that CCK applied iontophoretically to STT cells resulted in an inhibition. It has recently been reported that CCK has an opiate antagonist action (Faris et al., 1983) and that it excites dorsal horn interneurons (Jeftinija et al., 1981). On the other hand, Doi and Jurna (1982) found that intrathecally applied CCK had no effect on the responses of ascending (presumed STT) tract cells to $\mathrm{A} \delta$ and $\mathrm{C}$ fiber volleys in the rat. By contrast, we found that both CCK and enkephalin caused an inhibition of STT cells, and the actions summed. However, these findings should not be taken as conflicting with observations made at a behavioral level. The actions of CCK injected intrathecally could be quite complex and the end result may not be reflected in the discharges of a single population of ascending tract cells.
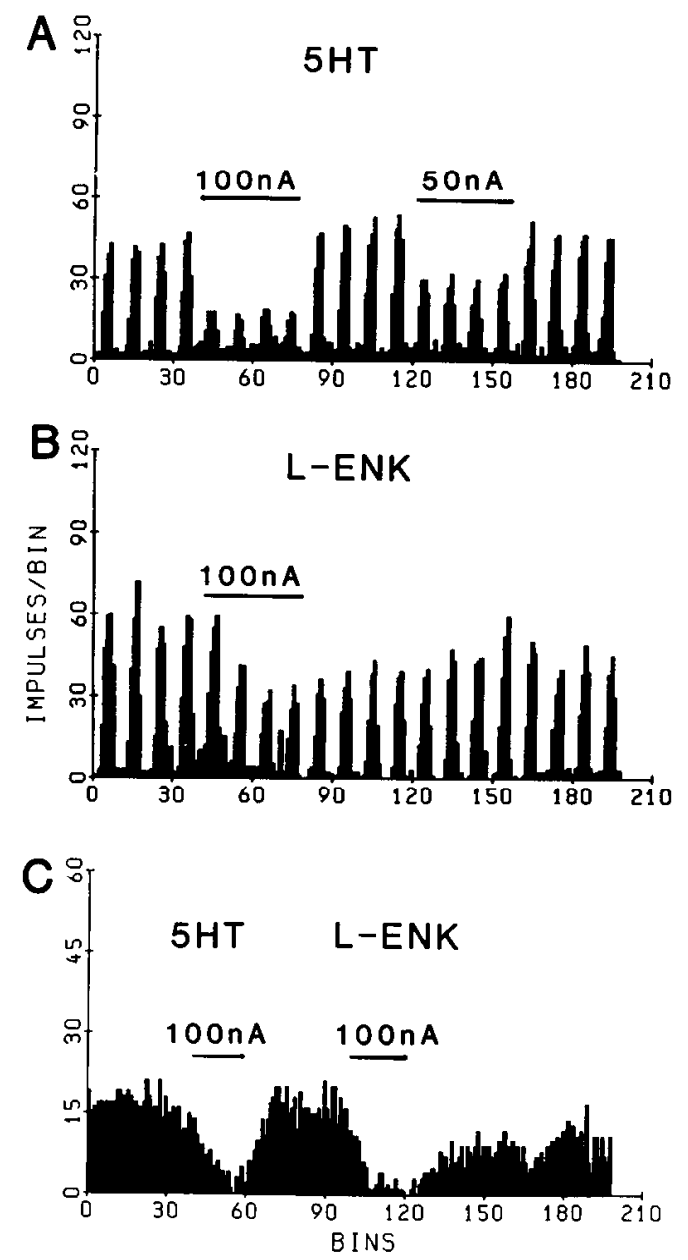

Figure 6. Comparison of 5-hydroxytryptamine ( $5 H T)$ and LENK action on an STT cell. $A$ and $B$, Single-pass peristimulus time histograms illustrating 5HT and L-ENK inhibition of pulsed Glu responses, respectively. $C$, Comparison of $5 \mathrm{HT}$ and L-ENK on pinch-evoked activity.
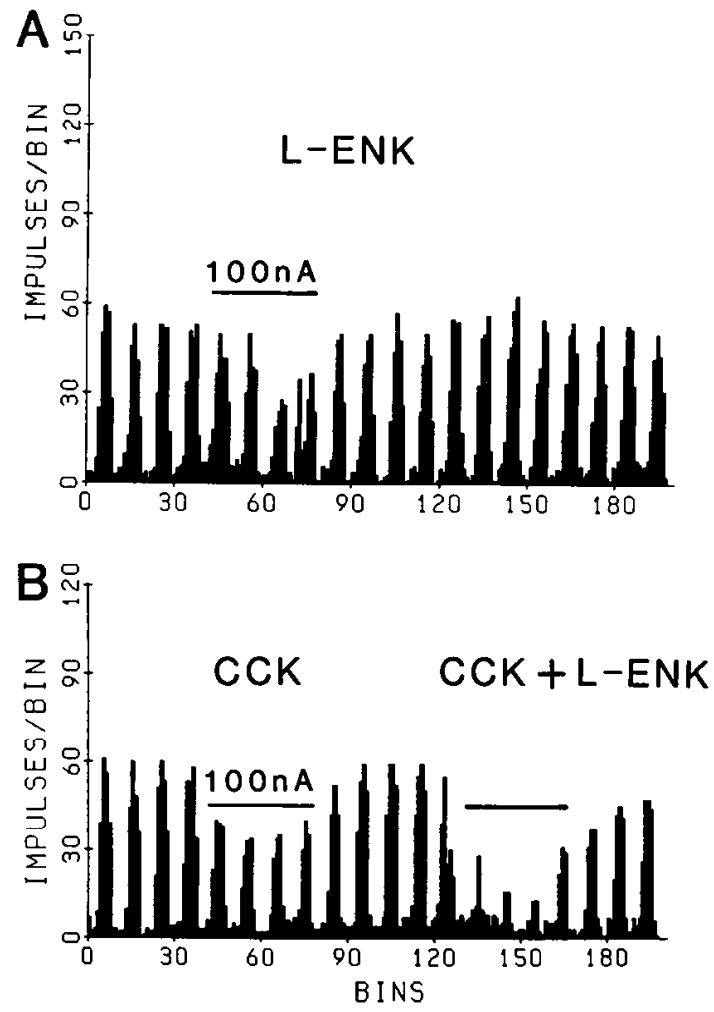

Figure 7. Effects of L-ENK and CCK on activity of STT cell. The location and receptive field characteristics of this cell are shown in Figure $2 A$. A, L-ENK inhibition of Glu-induced responses. $B$, Inhibition of pulsed Glu responses by CCK and strong reduction of Glu responses by application of CCK and L-ENK simultaneously, both at $100 \mathrm{nA}$.

The results of this study and those reported in the companion paper (Willcockson et al., 1984) show that primate spinothalamic tract cells can be excited or inhibited by a variety of candidate neurotransmitters found in synaptic endings of primary afferent fibers, interneurons, and descending tracts within the dorsal horn. A future task will be to determine in detail which neural systems make use of particular transmitters and how the activity of each system regulates the activity of spinothalamic cells and hence, presumably, the transmission of information related to pain sensation to the thalamus and cerebral cortex.

\section{References}

Aronin, N., M. DiFiglia, A. S. Liotta, and J. B. Martin (1981) Ultrastructural localization and biochemical features of immunoreactive Leu-enkephalin in monkey dorsal horn. J. Neurosci. 1: 561-577.

Barker, J. L., T. C. Smith, and J. H. Neale (1978) Multiple membrane actions of enkephalin revealed using cultured spinal neurons. Brain Res. 154: 153-158.

Belcher, G., and R. W. Ryall (1978) Differential excitatory and inhibitory effects of opiates on non-nociceptive and nociceptive neurones in the spinal cord of the cat. Brain Res. 145: 303-314.

Bowker, R. M., H. W. M. Steinbusch, and J. D. Coulter (1981) Serotonergic and peptidergic projections to the spinal cord demonstrated by a combined retrograde HRP histochemical and immunocytochemical staining method. Brain Res. 211: 412-417. 
Chan-Palay, V. (1979) Combined immunocytochemistry and autoradiography after in vivo injections of monoclonal antibody to substance $\mathrm{P}$ and ${ }^{3} \mathrm{H}$-serotonin: Co-existence of two putative transmitters in single raphe cells and fiber plexuses. Anat. Embryol. 156: 241-254.

Chan-Palay, V., and S. L. Palay (1977) Immunocytochemical identification of substance $P$ cells and their processes in rat sensory ganglia and their terminals in the spinal cord: Light microscopic studies. Proc. Natl. Acad. Sci. U. S. A. 74: 35973601.

Chung, J. M., D. R. Kenshalo, Jr., K. D. Gerhart, and W. D. Willis (1979) Excitation of primate spinothalamic neurons by cutaneous C-fiber volleys. J. Neurophysiol. 42: 1354-1369.

Chung, J. M., Z. R. Fang, C. L. Cargill, and W. D. Willis (1983) Prolonged, naloxone-reversible inhibition of the flexion reflex in the cat. Pain 15: 35-53.

Davies, J., and A. Dray (1980) Depression and facilitation of synaptic responses in cat dorsal horn by substance $\mathrm{P}$ administered into substantia gelatinosa. Life Sci. 27: 2037-2042.

DiFiglia, M., N. Aronin, and S. E. Leeman (1982) Light microscopic and ultrastructural localization of immunoreactive substance $\mathrm{P}$ in the dorsal horn of monkey spinal cord. Neuroscience $7:$ 1127-1139.

Doi, T., and I. Jurna (1982) Analgesic effect of intrathecal morphine demonstrated in ascending nociceptive activity in the rat spinal cord and ineffectiveness of caerulein and cholecystokinin octapeptide. Brain Res. 234: 399-407.

Dostrovsky, J., and B. Pomeranz (1973) Morphine blockade of amino acid putative transmitters on cat spinal cord sensory interneurones. Nature New Biol. 246: 222-224.

Dostrovsky, J. O., and B. Pomeranz (1976) Interaction of iontophoretically applied morphine with responses of interneurons in cat spinal cord. Exp. Neurol. 52: 325-338.

Duggan, A. W., J. G. Hall, and P. M. Headley (1977a) Suppression of transmission of nociceptive impulses by morphine: Selective effects of morphine administered in the region of the substantia gelatinosa. Br. J. Pharmacol. 61: 65-76.

Duggan, A. W., J. G. Hall, and P. M. Headley (1977b) Enkephalins and dorsal horn neurones of the cat: Effect on responses to noxious and innocuous skin stimuli. Br. J. Pharmacol. 61: 399-408.

Duggan, A. W., B. T. Griersmith, P. M. Headley, and J. G. Hall (1979) Lack of effect by substance $P$ at sites in the substantia gelatinosa where met-enkephalin reduces the transmission of nociceptive impulses. Neurosci. Lett. 12: 313-317.

Duggan, A. W., S. M. Johnson, and C. R. Morton (1981) Differing distributions of receptors for morphine and met-5enkephalinamide in the dorsal horn of the cat. Brain Res. 229: 379-387.

Emson, P. C. (1979) Peptides as neurotransmitter candidates in the mammalian CNS. Prog. Neurobiol. 13: 61-116.

Faris, P. L., B. R. Komisaruk, L. R. Watkins, and D. J. Mayer (1983) Evidence for the neuropeptide cholecystokinin as an antagonist of opiate analgesia. Science $219: 310-312$.

Fields, H. L., P. C. Emson, B. K. Leigh, R. F. T. Gilbert, and L. L. Iversen (1980) Multiple opiate receptor sites on primary afferent fibres. Nature (Lond.) 284: 351-353.

Frederickson, R. C. A., V. Burgis, C. E. Harrell, and J. D. Edwards (1978) Dual actions of substance $P$ on nociception: Possible role of endogenous opioids. Science 199: 1359-1362.

Gibson, S. J., J. M. Polak, S. R. Bloom, and P. D. Wall (1981) The distribution of nine peptides in rat spinal cord with special emphasis on the substantia gelatinosa and on the area around the central canal (lamina X). J. Comp. Neurol. 201: 65-79.

Gilbert, R. F. T., P. C. Emson, S. P. Hunt, G. W. Bennett, C. A. Marsden, B. E. B. Sandberg, H. W. M. Steinbusch, and A. A. J. Verhofstad (1982) The effects of monoamine neuro- toxins on peptides in the rat spinal cord. Neuroscience $7: 69$ 87.

Glazer, E. J., and A. I. Basbaum (1981) Immunohistochemical localization of leucine-enkephalin in the spinal cord of the cat: Enkephalin-containing marginal neurons and pain modulation. J. Comp. Neurol. 196: 377-389.

Gozlan, H., G. Le Gal La Salle, R. Michelot, and Y. Ben-Ari (1977) Rapid degradation of substance $P$ and related peptides during microiontophoretic experiments. Neurosci. Lett. 6: 27-33.

Guyenet, P. G., E. A. Mroz, G. K. Aghajanian, and S. E. Leeman (1979) Delayed iontophoretic ejection of substance P from glass micropipettes: Correlation with time-course of neural excitation in vivo. Neuropharmacology 18: 553-558.

Henry, J. L. (1976) Effects of substance $P$ on functionally identified units in cat spinal cord. Brain Res. 114: 439-451.

Henry, J. L., K. Krnjević, and M. E. Morris (1975) Substance $\mathrm{P}$ and spinal neurones. Can. J. Physiol. Pharmacol. 53: 423432.

Hökfelt, T., K. Fuxe, O. Johansson, S. Jeffcoate, and N. White (1975a) Thyrotropin releasing hormone (TRH)-containing nerve terminals in certain brain stem nuclei and in the spinal cord. Neurosci. Lett. 1: 133-139.

Hökfelt, T., J. O. Kellerth, G. Nilsson, and B. Pernow (1975b) Experimental immunohistochemical studies on the localization of substance $P$ in cat primary sensory neurons. Brain Res. 100: 235-252.

Hökfelt, T., R. Elde, O. Johansson, R. Luft, G. Nilsson, and A. Arimura (1976) Immunohistochemical evidence for separate populations of somatostatin-containing and substance $\mathrm{P}$ containing primary afferent neurons in the rat. Neuroscience 1: 131-136.

Hökfelt, T., A. Ljungdahl, H. Steinbusch, A. Verhofstad, G. Nilsson, E. Brodin, B. Pernow, and M. Goldstein (1978) Immunohistochemical evidence of substance P-like immunoreactivity in some 5-hydroxytryptamine-containing neurons in the rat central nervous system. Neuroscience 3: 517538.

Hökfelt, T., L. Terenius, H. G. J. M. Kuypers, and O. Dann (1979) Evidence for enkephalin immunoreactive neurons in the medulla oblongata projecting to the spinal cord. Neurosci Lett. 14: 55-60.

Hunt, S. P., J. S. Kelly, and P. C. Emson (1980) The electron microscopic localization of methionine-enkephalin within the superficial layers (I and II) of the spinal cord. Neuroscience 5 : $1871-1890$.

Hunt, S. P., J. S. Kelly, P. C. Emson, J. R. Kimmel, R. J. Miller, and J. Y. Wu (1981) An immunohistochemical study of neuronal populations containing neuropeptides or $\gamma$-aminobutyrate within the superficial layers of the rat dorsal horn. Neuroscience 6: 1883-1898.

Jeftinija, S., V. Miletić, and M. Randic (1981) Cholecystokinin octapeptide excites dorsal horn neurons both in vivo and in vitro. Brain Res. 213: 231-236.

Jessell, T. M., and L. L. Iversen (1977) Opiate analgesics inhibit substance $P$ release from rat trigeminal nucleus. Nature (Lond.) 268: 549-551.

Johansson, O., T. Hökfelt, B. Pernow, S. L. Jeffcoate, N. White, H. W. M. Steinbusch, A. A. J. Verhofstad, P. C. Emson, and E. Spindel (1981) Immunohistochemical support for three putative transmitters in one neuron: Coexistence of 5-hydroxytryptamine, substance $\mathrm{P}$ - and thyrotropin releasing hormone-like immunoreactivity in medullary neurons projecting to the spinal cord. Neuroscience $6: 1857-1881$.

Kardon, F. C., A. Winokur, and R. D. Utiger (1977) Thyrotropin-releasing hormone (TRH) in rat spinal cord. Brain Res. 122: 578-581.

Krnjevic, K., and M. E. Morris (1974) An excitatory action of 
substance $\mathbf{P}$ on cuneate neurones. Can. J. Physiol. Pharmacol. 52: 736-744.

LaMotte, C., C. B. Pert, and S. H. Snyder (1976) Opiate receptor binding in primate spinal cord: Distribution and changes after dorsal root section. Brain Res. 112: 407-412.

MacDonald, R. L., and P. G. Nelson (1978) Specific-opiateinduced depression of transmitter release from dorsal root ganglion cells in culture. Science 199: 1449-1451.

Maderdrut, J. L., T. L. Yaksh, P. Petrusz, and V. L. W. Go (1982) Origin and distribution of cholecystokinin-containing nerve terminals in the lumbar dorsal horn and nucleus caudalis of the cat. Brain Res. 243: 363-368.

Miletić, V., and M. Randić (1979) Neurotensin excites cat spinal neurones located in laminae I-III. Brain Res. 169: 600-604.

Mudge, A. W., S. E. Leeman, and G. D. Fischbach (1979) Enkephalin inhibits release of substance $\mathbf{P}$ from sensory neurons in culture and decreases action potential duration. Proc. Natl. Acad. Sci. U. S. A. 76: 526-530.

Murase, K., L. Urban, and M. Randic (1983) Actions of substance $\mathrm{P}$ on rat spinal dorsal horn neurons. In: Symposium on Microelectrophoretic Investigation of Mammalian Central Transmitters. Satellite Symposium of XXIXth International Congress of Physiological Science, Canberra, Australia, abstr. p. 23.

Nicoll, R. A., C. Schenker, and S. E. Leeman (1980) Substance $\mathrm{P}$ as a transmitter candidate. Annu. Rev. Neurosci. 3: 227268.

Peet, M. J., R. Malik, and D. R. Curtis (1983) Post-excitatory depression of neuronal firing by acidic amino acids and acetylcholine in the cat spinal cord. Brain Res. 263: 162-166.

Pickel, V. M., D. J. Reis, and S. E. Leeman (1977) Ultrastructural localization of substance $P$ in neurons of the rat spinal cord. Brain Res. 122: 534-540.

Piercey, M. F., F. J. Einspahr, P. J. K. Dobry, L. A. Schroeder, and R. P. Hollister (1980) Morphine does not antagonize the substance $\mathrm{P}$ mediated excitation of dorsal horn neurons. Brain Res. 186: 421-434.

Puil, E. (1981) S-Glutamate: Its interactions with spinal neurons. Brain Res. Rev. 3: 229-322.

Randić, M., and V. Miletić (1977) Effect of substance $P$ in cat dorsal horn neurones activated by noxious stimuli. Brain Res. 128: 164-169.

Randić, M., and V. Miletić (1978) Depressant actions of methionine-enkephalin and somatostatin in cat dorsal horn neurones activated by noxious stimuli. Brain Res. 152: 196202.

Randić, M., E. Carstens, M. Zimmermann, and D. Klumpp (1982) Dual effects of substance $P$ on the excitability of single cutaneous primary afferent $\mathrm{C}$ - and A-fibers in the cat spinal cord. Brain Res. 233: 389-393.

Ruda, M. A. (1982) Opiates and pain pathways: Demonstration of enkephalin synapses on dorsal horn projection neurons.
Science 215: 1523-1525.

Sastry, B. R. (1979a) Presynaptic effects of morphine and methionine-enkephalin in feline spinal cord. Neuropharmacology 18: 367-375.

Sastry, B. R. (1979b) Substance $P$ effects on spinal nociceptive neurones. Life Sci. 24: 2169-2178.

Satoh, M., S. I. Kawajiri, Y. Ukai, and M. Yamamoto (1979) Selective and nonselective inhibition by enkephalins and noradrenaline of nociceptive response of lamina $V$ type neurons in the spinal dorsal horn of the rabbit. Brain Res. 177: 384-387.

Sjölund, B. H., and M. B. E. Eriksson (1979) The influence of naloxone on analgesia produced by peripheral conditioning stimulation. Brain Res. 173: 295-301.

Takahashi, T., and M. Otsuka (1975) Regional distribution of substance $P$ in the spinal cord and nerve roots of the cat and the effect of dorsal root section. Brain Res. 87: 1-11.

Trevino, D. L., J. D. Coulter, and W. D. Willis (1973) Location of cells of origin of spinothalamic tract in lumbar enlargement of the monkey. J. Neurophysiol. 36: 750-761.

Willcockson, W. S., J. M. Chung, Y. Hori, K. H. Lee, and W. D. Willis (1983) Iontophoretic study of biogenic amine and peptide effects on primate spinothalamic tract cells. Soc. Neurosci. Abstr. 9: 1.

Willcockson, W. S., J. M. Chung, Y. Hori, K. H. Lee, and W. D. Willis (1984) Effects of iontophoretically released amino acids and amines on primate spinothalamic tract cells. J. Neurosci. 4: 732-740.

Woolf, C. J., and M. Fitzgerald (1981) Lamina-specific alteration of C-fibre evoked activity by morphine in the dorsal horn of the rat spinal cord. Neurosci. Lett. 25: 37-41.

Woolf, C. J., D. Mitchell, and G. D. Barrett (1980) Antinociceptive effect of peripheral segmental electrical stimulation in the rat. Pain 8: 237-252.

Yaksh, T. L. (1981) Spinal opiate analgesia: Characteristics and principles of action. Pain 11: 293-346.

Yaksh, T. L., and R. P. Elde (1981) Factors governing release of methionine enkephalin-like immunoreactivity from mesencephalon and spinal cord of the cat in vivo. J. Neurophysiol. 46: 1056-1075.

Yaksh, T. L., E. O. Abay, and V. L. W. Go (1982) Studies on the location and release of cholecystokinin and vasoactive intestinal peptide in rat and cat spinal cord. Brain Res. 242: 279-290.

Zieglgänsberger, W., and H. Bayerl (1976) The mechanism of inhibition of neuronal activity by opiates in the spinal cord of cat. Brain Res. 115: 111-128.

Zieglgänsberger, W., and I. F. Tulloch (1979a) Effects of substance $P$ on neurones in the dorsal horn of the spinal cord of the cat. Brain Res. 166: 273-382.

Zieglgänsberger, W., and I. F. Tulloch (1979b) The effects of methionine- and leucine-enkephalin on spinal neurones of the cat. Brain Res. 167: 53-64. 